\title{
Kyphosis in a free-living Marisora brachypoda (Squamata: Scincidae) from Utila Island, Honduras
}

\author{
CRISTINA ARRIVILLAGA ${ }^{1,2, *} \&$ TOM W. BROWN ${ }^{1}$ \\ ${ }^{1}$ Kanahau Utila Research and Conservation Facility, Isla de Utila, IB 34201, Honduras \\ ${ }^{2}$ Crees Foundation. Fundo Mascoitania, Manu, Madre de Dios, Peru \\ ${ }^{*}$ Corresponding author e-mail: cristinaarrivillaga@gmail.com
}

$T_{\text {titom }}^{\text {he }}$ he skink Marisora brachypoda (Taylor, 1956) is known from low to moderate elevations in Central America. In Honduras, the species is widespread in open habitats across much of the mainland and is reported on Utila Island (McCranie, 2018). Utila Island is part of the Honduran Department of the Bay Islands, being the westernmost island of the three major Bay Islands (Utila, Roatan, Guanaja) off the Caribbean coast of Honduras (McCraine, 2018). Notably, populations of Marisora on the islands of Roatan and Guanaja represent a cryptic endemic species, $M$. roatanae (Hedges \& Conn, 2012), while populations occurring on Utila belong to M. brachypoda (McCranie \& Orellano, 2014).

On multiple occasions over the course of April and May of 2018, we observed an adult male $M$. brachypoda with a visible vertical curvature of the spine, basking regularly on a tree trunk ca. $2.2 \mathrm{~m}$ high outside the Kanahau Utila Research and Conservation Facility (KURCF) $\left(16.119383^{\circ} \mathrm{N}, 86.884989^{\circ} \mathrm{W}\right.$, WGS 84). Despite its visible deformity, the skink appeared to move and behave in a normal way, being extremely quick and agile whilst moving up and down the tree. On 25 May 2018, 13:00 h, we managed to capture and inspect the individual while collecting morphological data (Snout vent length: $70.4 \mathrm{~mm}$; tail length: $64 \mathrm{~mm}$, weight: $7.3 \mathrm{~g}$ ). Upon external visual inspection, the kyphosis started in the mid-section of its body, continuing all the way to the end of its tail (Fig. 1.). The individual also presented signs of caudal autotomy and subsequent regeneration, which can be observed in Figure 1. To our knowledge, this is the first evidence of kyphosis in the genus Marisora.

Malformations such as the kyphosis seen in this individual have been reported in other free-living populations of lizards (Gering, 2009; Garin-Barrio et al., 2011; Pérez-Delgadillo et al., 2015; Ortiz-Medina \& Valdez-Villavicencio, 2016; ValdezVillavicencio et al., 2016), as well as captive populations of skinks (Cooper et al., 1982). Bellairs (1981) discussed the aetiology and pathogenesis of various developmental abnormalities of reptiles, and stated that they are of either genetic or environmental origin. In reptiles, spinal malformations can arise owing to incorrect conditions during the incubation of eggs, i.e. excessively low or high temperatures and low relative humidity; though notably, "toxins and pollutants" (e.g. insecticides) might also be responsible for malformations observed in wild reptiles (Bellairs, 1981). Additional studies have also shown that inbreeding of reptile populations with low genetic diversity

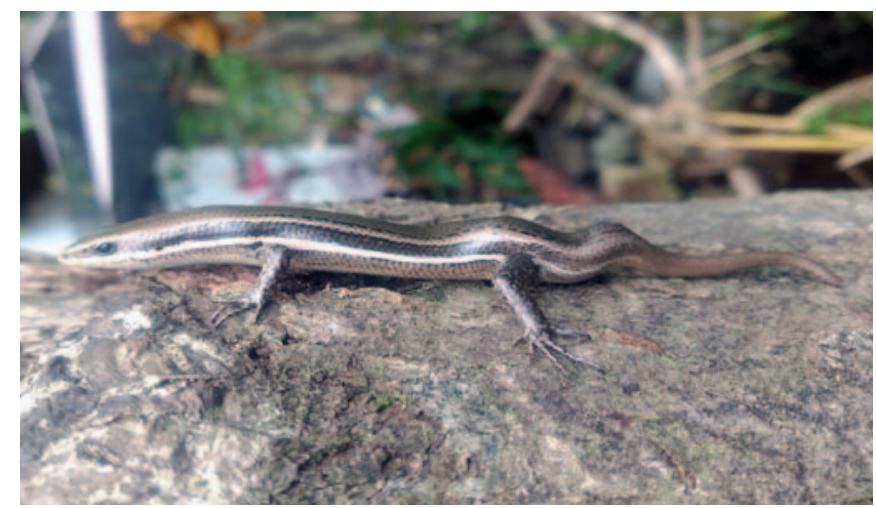

Figure 1. Lateral view of the adult male M. brachypoda with kyphosis

can cause malformations (Madsen et al., 1992; Olsson et al., 1994; 1996), and that spinal malformations can be caused by metabolic bone diseases (Frye, 1991).

In this case, as our diagnosis is purely external, we cannot safely confirm the cause of the deformity in M. brachypoda. While we were unable to collect and radiograph the specimen, ideally, such practice should be followed as it allows for more detailed investigation of skeletal abnormalities. Nonetheless, our observations demonstrate that individuals can survive under natural circumstance with such a developmental anomaly.

\section{ACKNOWLEDGEMENTS}

We thank Kanahau Utila Research \& Conservation Facility for the foundation and support from which to perform herpetological research on Utila Island, as well as the KURCF research and management team, local field guides and assisting volunteers. Special thanks go to John E. Cooper for his veterinary insights regarding similar developmental abnormalities in skinks at Jersey Zoo and helpful review of this note. All biological data were collected with permission issued by Instituto Nacional de Conservación y Desarrollo Forestal, Áreas Protegidas y Vida Silvestre (ICF), Tegucicalpa, Honduras.

\section{REFERENCES}

Bellairs, A. d'A. (1981). Congenital and developmental diseases. In: Diseases of the Reptilia. Eds Cooper, J.E. and 
Jackson, O.F., pp. 469-485. Academic Press, London

Cooper, J.E., Arnold, L. \& Henderson, G.M. (1982). A developmental abnormality in the Round Island skink Leiolopisma telfairii. Dodo, Journal of the Jersey Wildlife Preservation Trust 19: 78-81.

Frye, F. I. (1991). Biomedical and Surgical Aspects of Captive Reptile Husbandry. Krieger Publishing Company, Malabar, Florida, United States. 712 pp.

Garin-Barrio, I., Sanz-Azkue, I., Goza, A. \& Bandres, A. (2011). Un caso de cifosis en Podarcis pityusensis (Boscá, 1883), lagartija introducida en el peñón de Gaztelugatxe (Bizkaia). Munibe 59: 103-109.

Gering, P. (2009). A remarkable case of malformation in a free-living individual of Furcifer pardalis (Cuvier, 1829) from northern Madagascar. Herpetology Notes 2: 223-225

Hedges, S.B. \& Conn, C. E. (2012). A new skink fauna from Caribbean Islands (Squamata; Mabuyidae, Mabuyinae). Zootaxa: 3288.

Madsen, T., Shine, R., Loman, J. \& Håkansson, T. (1992). Why do female adders copulate so frequently? Nature 355: 440-441.

McCranie, J. R. (2018). The Lizards, Crocodiles, and Turtles of Honduras. Systematics, Distribution, and Conservation. Bulletin of the Museum of Comparative Zoology, Special Publications Series, No. 2. 339-343.
McCranie, J. R. \& Orellana, L. V. (2014). New island records and updated nomenclature of amphibians and reptiles from the Islas de la Bahía, Honduras. Herpetology Notes 7: 41-49.

Olsson, M. (1994). Nuptial coloration in the sand lizard, Lacerta agilis: an intra-sexually selected cue to fighting ability. Animal Behaviour 44: 386-388.

Olsson, M., Gullberg, A. \& Tegelström, H. (1996). Malformed offspring, sibling matings, and selection against inbreeding in the sand lizard (Lacerta agilis). Journal of Evolutionary Biology 9: 229-242.

Ortiz-Medina, J. A. \& J. H. Valdez-Villavicencio. (2016). Norops sericeus (Hallowell, 1856). Kyphosis and scoliosis. Mesoamerican Herpetology 3: 725-726

Pérez-Delgadillo, A. G., Quintero-Díaz, G. E. Carbajal-Márquez, R. A. \& García-Balderas, C. M. (2015). Primer reporte de cifosis en Sceloporus toquatus (Squamata: Phrynosomatidae) en el estado de Aguascalientes, México. Revista Mexicana de Biodiversidad 86: 272-274.

Valdez-Villavicencio, J. H., Hollingsworth, B. D. \& GalinaTessario, P. (2016). Sceloporus vandenburgianus (Cope, 1986). Kyphosis and scoliosis. Mesoamerican Herpetology 3: 488-490.

Accepted: 27 May 2019 